\title{
Problems in the laboratory assessment of antifungal activity
}

\author{
F. C. ODDS \\ Ph.D. \\ Department of Microbiology, University of Leicester
}

\begin{abstract}
Summary
The end points of tube dilution tests for minimal inhibitory concentrations of miconazole and flucytosine against Candida albicans were difficult to evaluate because partial inhibition was noted over a wide range of antifungal concentrations. This problem was not encountered with amphotericin B. Partial inhibition of Candida arose because of reductions in yeast growth rate and of cell yield. Different sizes of yeast inocula were differentially inhibited by the same concentration of antifungal agent.

An in vitro apparatus was described in which miconazole formulated as commercial creams, pessaries and medicated tampons for intravaginal application could be assessed for its inhibitory action in vitro.
\end{abstract}

\section{Introduction}

Laboratory tests for antifungal sensitivities are usually restricted to determinations of the minimal inhibitory concentration (MIC) of pure antifungal substance for a given fungal isolate. The relationship between MIC and in vivo effectiveness of a given compound is not always clear, and in any case the commercial formulations of an antifungal that are used clinically are not, as a rule, tested in the laboratory. Antifungal MIC determinations are known to be affected by such performance variables as the composition of the culture medium (Hoeprich and Finn, 1972), the presence or absence of serum proteins (Sreedhara Swamy, Sirsi and Ramonanda Rao, 1974) and the size of the test inoculum (Galgiani and Stevens, 1976). In this presentation attention is drawn to an additional difficulty of assessment of MIC presented by apparent partial inhibition of yeast cultures by flucytosine and miconazole, and a suggestion is given for a new approach to laboratory evaluation of commercial antifungal formulations in vitro.

\section{Materials and methods}

Three strains of Candida albicans, 73/004, NCPF 3153 and ATCC 28366 were used in the experiments. They were maintained on slopes of Sabouraud's dextrose agar (SDA, Difco) and inocula were prepared as aqueous suspensions of yeasts from slopes of SDA incubated for $18 \mathrm{hr}$ at $37^{\circ} \mathrm{C}$. Yeast cell numbers were estimated by haemocytometer counts.

For experiments to determine MIC and effects of inoculum size on MIC, C. albicans was inoculated into 10-ml lots of YNB (yeast nitrogen base, Difco) plus $1 \%$ glucose in $16-\mathrm{mm}$ diameter sterile test tubes, and incubated at $37^{\circ} \mathrm{C}$. Three antifungals were used in the tests: amphotericin B complexed with buffered desoxycholate (Fungizone i.v., E.R. Squibb) and flucytosine were dissolved in sterile water, miconazole was dissolved in acetone. The antifungal solutions were diluted in YNB medium to concentrations appropriate for the experiments. For determination of $C$. albicans growth rates and cell yields in the presence of antifungals, the experimental conditions were similar except that culture volumes of $100 \mathrm{ml}$ in $250-\mathrm{ml}$ flasks were shaken at 160 r.p.m. and $37^{\circ} \mathrm{C}$. Turbidity of cultures was determined spectrophotometrically at $550 \mathrm{~nm}$ against a water blank.

The apparatus for in vitro experiments with intravaginal formulations of antifungals is illustrated in Fig. 1. The apparatus was sterilized in an autoclave. A miconazole vaginal pessary, miconazole-coated tampon or $5 \mathrm{ml}$ of miconazole vaginal cream was introduced in the $1.4-\mathrm{cm}$ diameter dialysis sac, and 4-6 $\mathrm{ml}$ of phosphate buffered saline (PBS), $10 \%$ bovine serum albumin (Sigma) in PBS or vaginal washings in PBS obtained from routine gynaecology out-patients was added to the dialysis sac at zero time. Yeast nitrogen base medium $(30 \mathrm{ml})$ inoculated to $10^{6}$ C. albicans ATCC $28366 / \mathrm{ml}$ was added aseptically to the chamber surrounding the dialysis sac. The apparatus was incubated at $37^{\circ} \mathrm{C}$ and samples of the $C$. albicans culture were removed aseptically at intervals for estimation of yeast numbers with a haemocytometer. Just before each sample was removed the culture was homogenized by aeration with a sterile Pasteur pipette and rubber bulb. A control apparatus contained a plain tampon within the dialysis sac. The rationale of the model was that miconazole within the cream, pessary, etc. 


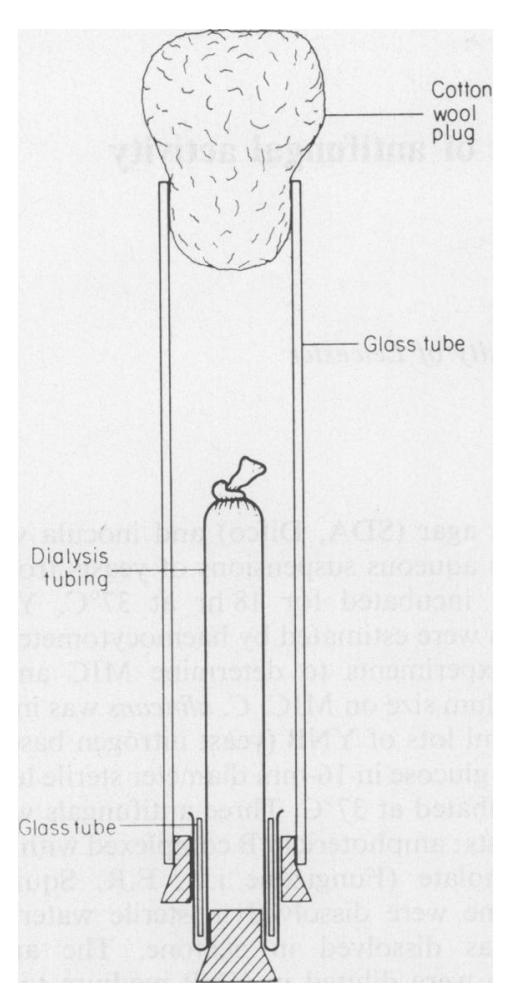

Fig. 1. Apparatus for in vitro assessment of intravaginal antifungal formulations. The antifungal cream, pessary or tampon was introduced in the dialysis sac together with buffered saline, protein solution or vaginal washings. A culture of $C$. albicans was placed in the space surrounding the dialysis sac.

would have to diffuse through the dialysis membrane, without being bound to proteins, in order to inhibit the $C$. albicans culture.
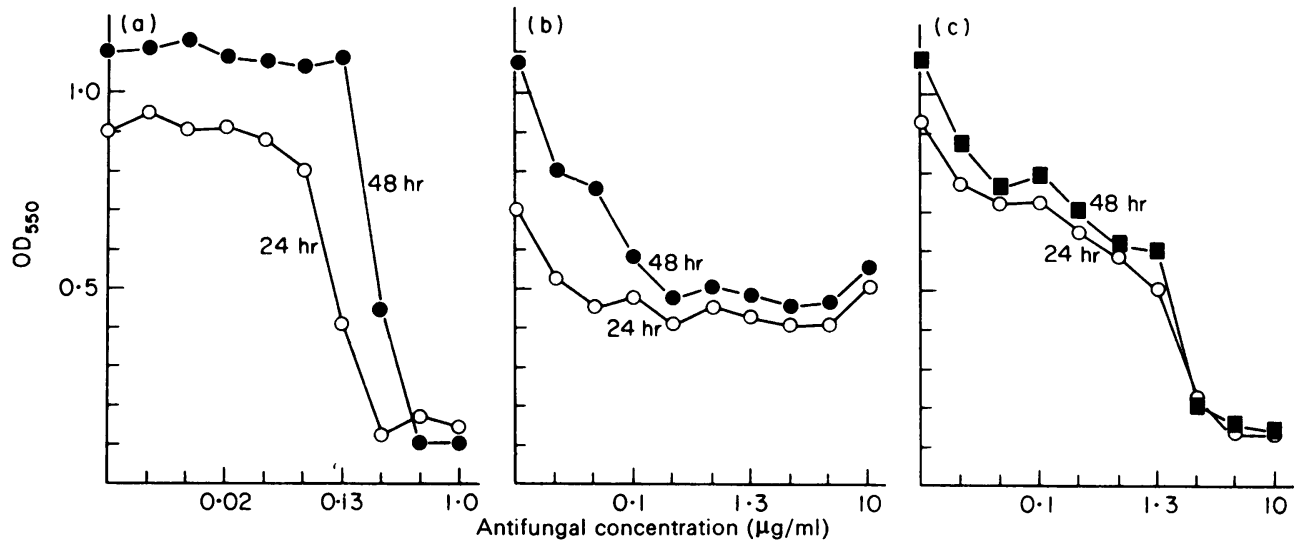

FIG. 2. Turbidity of a culture of $C$. albicans in tube dilution tests for antifungal sensitivities. (a) amphotericin B, (b) flucytosine, (c) miconazole. Two other strains tested produced similar curves.
Results

MIC determinations

When the turbidity of 3 strains of $C$. albicans cultures was measured 24 and $48 \mathrm{hr}$ after inoculation at $10^{8} / \mathrm{ml}$ into media containing doubling dilutions of antifungals, different inhibitory effects were noted for amphotericin B, flucytosine and miconazole (Fig. 2). As the concentration of amphotericin B increased, the culture turbidity remained essentially the same as that of an amphotericin-free control until at inhibitory concentrations of amphotericin B there was an abrupt fall in culture turbidity (Fig. 2a). The change in culture turbidity with amphotericin B concentration occurred over 3 antifungal dilutions when turbidities were measured after $24 \mathrm{hr}$ 's incubation, and over 2 dilutions after $48 \mathrm{hr}$. By contrast, with flucytosine, the culture turbidity fell steadily from maximum (no inhibition) to minimum (full inhibition) over at least 4 tube dilutions (Fig. 2b); that is, partial inhibition was noted over a 16-fold range of flucytosine concentration. For miconazole, partially inhibitory effects were observed over a 128-fold range of concentration for all 3 strains (Fig. 2c). The wide ranges of antifungal concentration over which partial inhibition was seen for flucytosine and miconazole rendered naked-ey determination of MIC highly liable to error.

In experiments where the inhibitory effects of the 3 test antifungals were assessed in terms of growth rate and cell yield of $C$. albicans ATCC 28366, it was observed that the effects of amphotericin B range from nil at $0.02 \mathrm{mg} / \mathrm{l}$ to fungicidal at $2.0 \mathrm{mg} / \bar{\Phi}$ (Table 1). Partial inhibition by this agent was achieved at $0.2 \mathrm{mg} / \mathrm{l}$. Flucytosine at concentrations up to $0.2 \mathrm{mg} / \mathrm{l}$ caused a reduction in maximum growth rate of the cultures but did not affect cell yield, while miconazole at concentrations from 0.2 to $20.0 \mathrm{mg} / \mathrm{l}$ reduced both growth rate and cell yield in proportion to concentration. 
TABLE 1. Growth rates and cell yields of $C$. albicans ATCC 28366 in the presence of antifungals (determined from growth curves of $C$. albicans)

\begin{tabular}{|c|c|c|c|c|c|c|}
\hline \multirow[b]{2}{*}{$\begin{array}{l}\text { Concentration } \\
(\mathrm{mg} / \mathrm{l})\end{array}$} & \multicolumn{2}{|c|}{ Amphotericin B } & \multicolumn{2}{|c|}{ Flucytosine } & \multicolumn{2}{|c|}{ Miconazole } \\
\hline & $\begin{array}{l}\text { Maximum } \\
\text { growth } \\
\text { rate } / \mathrm{hr}\end{array}$ & $\begin{array}{c}\text { Relative } \\
\text { cell } \\
\text { yield* }\end{array}$ & $\begin{array}{l}\text { Maximum } \\
\text { growth } \\
\text { rate/hr }\end{array}$ & $\begin{array}{c}\text { Relative } \\
\text { cell } \\
\text { yield* }\end{array}$ & $\begin{array}{c}\overline{\text { Maximum }} \\
\text { Growth } \\
\text { rate } / \mathrm{hr}\end{array}$ & $\begin{array}{c}\text { Relative } \\
\text { cell } \\
\text { yield* }\end{array}$ \\
\hline 0.00 & 0.82 & $1 \cdot 8$ & 0.82 & $1 \cdot 7$ & 0.79 & $1 \cdot 8$ \\
\hline 0.02 & 0.82 & $1 \cdot 8$ & 0.35 & 1.7 & & \\
\hline 0.02 & 0.52 & 0.5 & $0 \cdot 10$ & $1 \cdot 7$ & 0.71 & 1.8 \\
\hline $2 \cdot 00$ & 0.0 & $-\dagger$ & 0.06 & $-\ddagger$ & $0 \cdot 38$ & $1 \cdot 6$ \\
\hline $20 \cdot 00$ & & & & & 0.09 & 0.5 \\
\hline
\end{tabular}

* Calculated as $\log$ optical density (OD) 550 at stationary phase minus $\log \mathrm{OD}_{550}$ at zero time.

$\dagger$ Turbidity fell throughout experiment, indicating cell death.

$\ddagger$ No clear-cut stationary phase was attained within the time course of the experiment.

TABLE 2. Variation of $C$. albicans yield with inoculum size - data show $\mathrm{OD}_{550}$ after $48 \mathrm{hr}$ 's incubation

\begin{tabular}{ccccc}
\hline $\begin{array}{c}\text { Yeasts/ml } \\
\text { (initial) }\end{array}$ & $\begin{array}{c}\text { Control (no } \\
\text { antifungal) }\end{array}$ & $\begin{array}{c}\text { Amphotericin B } \\
(0.5 \mathrm{mg} / \mathbf{l})\end{array}$ & $\begin{array}{c}\text { Flucytosine } \\
(0.2 \mathrm{mg} / \mathbf{l})\end{array}$ & $\begin{array}{c}\text { Miconazole } \\
(0.5 \mathrm{mg} / \mathrm{l})\end{array}$ \\
\hline $10^{7}$ & 1.55 & 1.55 & 1.29 & 1.23 \\
$10^{6}$ & 1.53 & 1.54 & 0.76 & 0.66 \\
$10^{5}$ & 1.54 & 0.04 & 0.01 & 0.07 \\
$10^{4}$ & 1.55 & 0.04 & 0.02 & 0.04 \\
\hline
\end{tabular}

Variation of the inoculum size in tube MIC determinations led to different gross inhibitory effects on $C$. albicans for the same antifungal concentration (Table 2). Amphotericin B at $0.5 \mathrm{mg} / 1$ was fully inhibitory to inocula of $10^{5}$ yeasts $/ \mathrm{ml}$ and fully noninhibitory to inocula of $10^{6} / \mathrm{ml}$ or greater, whereas with flucytosine and miconazole, intermediate turbidity figures between those for the smallest and the largest inocula indicated inoculum-dependent partially inhibitory effects.

\section{Inhibition of $C$. albicans in the vaginal antifungal model}

The data in Table 3 show that all 3 miconazole vaginal formulations tested in the apparatus shown in Fig. 1 effectively inhibited the growth of $C$. albicans in the fluid surrounding the dialysis sac. The effects of the formulations were the same regardless of the presence or absence within the sac of albumin solution or vaginal washings. In experiments where the growth of $C$. albicans around the dialysis sac was monitored with time, the miconazole cream formulation was immediately fungistatic whereas the miconazole pessary and coated tampon formulations caused fungistasis after one yeast generation.

\section{Discussion}

This study has highlighted some of the difficulties that may confound precise determination of in vitro MIC for flucytosine or miconazole. A reasonably clear-cut MIC end point was achieved for amphotericin B, but in flucytosine and miconazole sensitivity tests the series of tubes contain cultures of steadily decreasing turbidity, which results in subjective, and therefore variable end-point determinations. For all 3 antifungals the inhibitory effects

TABLE 3. Total cell counts of $C$. albicans before and after incubation at $37^{\circ} \mathrm{C}$ for $24 \mathrm{hr}$ in culture fluid surrounding dialysis tube of model vagina. Essentially the same results were obtained regardless of the presence within the tube of $10 \%$ albumin solution or vaginal washings, so the data from all tests are pooled in the table

\begin{tabular}{llcc}
\hline & \multicolumn{2}{l}{$\log _{10}$ yeasts/ml, mean $( \pm$ s.e. mean $)$} & \\
\cline { 2 - 4 } $\begin{array}{l}\text { Preparation tested } \\
\text { in dialysis tube }\end{array}$ & per ml at zero time & per ml at $24 \mathrm{hr}$ & $\begin{array}{c}\text { Number of } \\
\text { replicates }\end{array}$ \\
\hline Plain tampon & $5 \cdot 9(0 \cdot 1)$ & $7 \cdot 5(0 \cdot 0)$ & 4 \\
Miconazole absorbent pessary & $5 \cdot 9(0 \cdot 2)$ & $6 \cdot 0(0 \cdot 2)$ & 5 \\
Miconazole cream & $6 \cdot 0(0 \cdot 0)$ & $5 \cdot 9(0 \cdot 1)$ & 4 \\
Miconazole pessary & $6 \cdot 0(0 \cdot 0)$ & $6 \cdot 3(0 \cdot 0)$ & 3 \\
\hline
\end{tabular}


varied enormously with the size of the test inoculum. Galgiani and Stevens (1976) recommended the routine use of turbidity measurements in antifungal MIC assays, since a $50 \%$ turbidity reduction figure proved to be more consistent and inoculumindependent than MIC. In view of the large range of concentration of miconazole and flucytosine over which partial inhibition of $C$. albicans was seen in the present study, it is clear that some objective, turbidity-based end-point is likely to be more reproducible from laboratory to laboratory; however, further experience with sensitivity tests will be required before such end-points may be related even circumstantially to the clinical efficacy of antifungal compounds. Inter-laboratory co-operation should, in time, lead to the introduction of a standard sensitivity test protocol for antifungal agents.

The experiments with the vaginal model apparatus (Fig. 1, Table 3) provide a preliminary indication that commercial formulations of antifungal agents may be as amenable to laboratory investigation as pure antifungal compounds. The model has demonstrated that miconazole, in 3 different intravaginal formulations, is rapidly released, without impediment by protein binding, in concentrations sufficient to inhibit the growth of a surrounding $C$. albicans culture: this in vitro finding broadly correlates with in vivo results obtained in clinical trials of miconazole (Odds, 1977).

\section{Acknowledgments}

The author wishes to thank Janssen Pharmaceutical Ltd for the gift of miconazole nitrate and its commercial formulations, Roche Products Ltd for the gift of flucytosine, and L. A. Fraser and A. Abbott for their skilled technical assistance.

\section{References}

Galgiani, J.N. \& Stevens, D.A. (1976) Antimicrobial sensitivity testing of yeasts: a turbidimetric technique independent of inoculum size. Antimicrobial Agents and Chemotherapy, 10, 721 .

HoEPrich, P.D. \& FinN, P.D. (1972) Obfuscation of the activity of antimicrobics by culture media. Journal of Infectious Diseases, 126, 353.

ODDS, F.C. (1977) Cure and relapse with antifungal therapy. Proceedings of the Royal Society of Medicine, 70 (Suppl. 4), 24.

Sreedhara Swamy, K.H., Sirsi, M. \& Ramananda Rao, G. (1974) Studies on the mechanism of action of miconazole: effect of miconazole on respiration and cell permeability of Candida albicans. Antimicrobial Agents and Chemo therapy, 5, 420. 